\title{
aniki
}

Revista Portuguesa da Imagem em Movimento Portuguese Journal of the Moving Image

\section{Jogo e conspiração em Hollywood: o Portugal que não foi}

\author{
Rui Lopes ${ }^{1}$
}

Na ficção audiovisual norte-americana anterior à II Guerra Mundial, Portugal praticamente não existia enquanto espaço geográfico dotado de uma iconografia própria ou de conotações políticas e de género cinematográfico. ${ }^{2}$ Já a mais de uma dúzia de filmes produzidos entre 1941 e 1945, em que Portugal (em particular Lisboa e arredores) é proeminentemente evocado ${ }^{3}$ implantou e consolidou elementos que ecoariam no cinema das décadas seguintes, incluindo uma atmosfera cosmopolita de romance e/ou intriga internacional (Dias 2015; Lopes 2017a; Lopes 2017b; Mateus 2010). ${ }^{4}$

Significa isto que a imagem cinematográfica de Portugal em Hollywood é forjada justamente num momento em que o Estado Novo procurar assegurar a sua sobrevivência, salvaguardando um lugar para a ditadura salazarista na reconfiguração geopolítica em curso. Inicialmente, o governo, convicto de que a guerra em breve retumbaria num acordo de paz equilibrado, mantivera a tradicional política de relações amigáveis com o Reino Unido. A partir do verão de 1940, no entanto, a aura de invencibilidade da Alemanha e a

\footnotetext{
${ }^{1}$ Instituto de História Contemporânea/Faculdade de Ciências Sociais e Humanas NOVA FCSH, Universidade NOVA de Lisboa, 1069-061 Lisboa, Portugal.

2 A pequena exceção que foi The Last Flight (1931) - um drama sobre veteranos americanos da I Guerra Mundial que, no terço final do filme, viajam até Lisboa - é notória precisamente por associar Portugal a dois cenários e ambientes que não tiveram reprodução em posteriores obras de Hollywood: uma tourada e uma feira popular.

${ }_{3}^{3}$ Pesquisa realizada quer na Internet (sobretudo no catálogo do American Film Institute [AFI] e Internet Movie Database), quer no arquivo da Academy of Motion Pictures Arts and Sciences indica a seguinte lista completa: Forbidden Passage (1941); One Night in Lisbon (1941); Affectionately Yours (1941); International Lady (1941); Casablanca (1942); The Lady Has Plans (1942); Journey for Margaret (1942); Three Hearts for Julia (1942); The Fallen Sparrow (1943); Storm Over Lisbon (1944); The Conspirators (1944); The Hairy Ape (1944); Voice in the Wind (1944); The House on $92^{\text {nd }}$ Street (1945).

${ }^{4}$ A mesma pesquisa e os respetivos visionamentos indica que estes elementos estão presentes pelo menos nas seguintes obras de Hollywood: Jewels of Brandenburg (1947); A Bullet for Joey (1955); Lisbon (1956); Flight to Hong Kong (1956); Pickup Alley (1957); The Secret Door (1964); 36 Hours (1965); A Man Could Get Killed (1966); Don't Raise the Bridge, Lower the River (1968); Hook, Line and Sinker (1969); The Last Run (1971); The Russia House (1990). Para além do cinema, também a ficção televisiva americana contribuiu para reproduzir estes elementos, tendo o mesmo método de pesquisa e visionamento servido para apurar a existência de pelo menos os seguintes casos: 'Lisbon', Biff Baker, U.S.A. (1953); 'Two Loves I Have', Schlitz Playhouse of Stars (1953); 'The Last Laugh', Wire Service (1957); 'Blind Spot', Man with a Camera (1958); 'Sink U-116!', Convoy (1965); 'The Last Man', Blue Light (1966); 'The Master's Touch Affair', The Man from U.N.C.L.E. (1967); 'A Thief is a Thief', It Takes a Thief (1968); ‘The Lisbon Beat', Madigan (1973).
} 
ameaça de uma agressão hispano-alemã, potenciada pelas divisões Panzer nos Pirenéus, levaram à adoção de uma postura mais equidistante, que incluiu concessões económicas ao Eixo, e Portugal tornou-se no seu principal fornecedor de volfrâmio (minério essencial para o material de guerra). Só já nos últimos anos do conflito, perante a viragem da guerra em favor dos Aliados, é que o Estado Novo transformou a tipicamente chamada (p. ex., Rosas 1994, 306/314) "neutralidade geométrica" em "neutralidade colaborante". Ainda assim, a cedência de bases açorianas à Grã-Bretanha (1943) e aos EUA (1944), bem como o embargo da venda de volfrâmio à Alemanha (1944), foram o culminar de tensas e prolongadas negociações (Andrade 2008; Antunes 1995; Ninhos 2013; Rodrigues 2008; Rosas 1994, 301-320).

As oscilações e ambiguidades da neutralidade portuguesa têm suscitado debate historiográfico, incluindo sobre a importância do risco de invasão, do oportunismo económico e das tendências próEixo do regime. Filipe Ribeiro de Meneses (2010, 222-273) apresenta Salazar como um isolacionista sem desejo de se envolver em desordens europeias, preocupado sobretudo com a preservação da integridade nacional e imperial. Para António Telo (2000, 361-363), os disfarçados esquemas de financiamento do Eixo derivaram, não de uma simpatia pelo mesmo, mas da sobrevalorização da sua capacidade de retaliação. Embora caracterizando Portugal como "o neutro próAliados" (por oposição a Espanha, "o neutro pró-Eixo”), Christian Leitz (2001, 144-174/185-187) enfatiza o oportunismo económico do Estado Novo, insistindo que foi este, mais do que o receio de retaliação nazi, que motivou as exportações de volfrâmio, o que explicaria a relutância em impor o embargo exigido pelos Aliados mesmo após a diminuição do poderio alemão. Esta interpretação parece coadunar-se com a de António Louçã $(2000,136)$, que conclui que Portugal forneceu a matéria-prima a preços exorbitantes, explorando a posição comercial de força face a uma Alemanha com termos de troca cada vez mais desfavoráveis. Porém, Louçã sublinha que a solidariedade antibolchevista foi o fator decisivo para a obstinada resistência de Salazar à exigência de um embargo (139-40). Também Manuel Loff (2008) desvaloriza o pragmatismo: centrandose no plano ideológico e discursivo, defende que o salazarismo se reviu nas conceções de fundo do projeto de reformulação internacional da comunidade eurofascista (que abarcava as ditaduras de Franco, Hitler e Mussolini). Indo mais longe na recusa de leituras pragmatistas - e do determinismo que daí pode advir - Alexandre Moreli (2017) argumenta que as políticas do Estado Novo não foram apenas uma resposta lógica a interesses económicos, militares e estratégicos: foram também o resultado de reações emocionais, propaganda e contactos pessoais, os quais culminaram numa ofensiva de charme por parte dos Aliados, que se estendeu até depois de o Eixo deixar de representar perigo iminente para o país.

Um aspeto ausente nos trabalhos sobre a neutralidade portuguesa é a expressão cinematográfica da mesma, em particular na ficção. No entanto, a análise do modo como Portugal foi então 
ficcionado ilumina novos ângulos sobre o papel da II Guerra Mundial na história do Estado Novo, incluindo sobre a visibilidade das tensões acima referidas. Através dessa análise, este artigo explorará o potencial do estudo do cinema para a história das relações internacionais, uma vez que a visão de Hollywood foi projetada não só em ecrãs americanos, mas para milhões de espetadores em diversos países, ora sob a forma de grande espetáculo, ora revisitada dentro do lar graças à ascensão da televisão no pós-guerra, o que veio a contribuir para a definição do lugar de Portugal no imaginário internacional. Ao mesmo tempo, o artigo explorará o potencial da história política para o estudo do cinema, uma vez que a II Guerra Mundial não só encorajou a elaboração de enredos relacionados com o território português - aproveitando o apelo dramático da concentração de refugiados e espiões na capital e refletindo a experiência das diversas figuras de Hollywood que por lá passaram a caminho dos EUA (Ribeiro 1941) - como condicionou o seu conteúdo. A imagem de Portugal criada durante este período resultou de variadas considerações e negociações, pelo que um entendimento dos elementos que a constituem passa também pela análise daqueles que não a constituem, isto é, das perspetivas propostas ao longo do processo de produção que ficaram pelo caminho - do país imaginado que não foi exibido, mas poderia ter sido.

É dessa dimensão que este artigo tratará. Começará por esboçar as condicionantes de Hollywood e a filmografia sobre Portugal que não chegou a existir, enquadrando o palco em que as produções eram moldadas e a escala de projetos não concretizados. O artigo examinará de perto os argumentos de dois projetos: The Gamblers (que não foi rodado) e The Conspirators (1944), reconstituindo diferentes fases da escrita e pré-produção a partir de coleções raramente usadas na historiografia portuguesa, consultadas na Academy of Motion Pictures Arts and Sciences, no Wisconsin Center for Film and Theater Research, na University of California Los Angeles e em arquivos nacionais dos EUA. O artigo mostrará como a simplificação narrativa em contexto de guerra, promovida quer pela máquina de propaganda oficial, quer pelos próprios estúdios, contribuiu para suavizar uma visão mais crítica da neutralidade portuguesa, da ditadura salazarista e da própria história do país.

\section{A indústria cinematográfica de guerra e o Portugal fora do ecrã}

Se a longa cadeia de produção de Hollywood era já de si composta por sucessivos elos passíveis de afetar o produto final, a entrada dos EUA na guerra, em dezembro de 1941, aumentou ainda mais o número de agentes com influência no processo. Os filmes só podiam ser exportados com a aprovação do Departamento de Censura do governo, de modo a assegurar que não se divulgavam neles segredos militares. O governo estabeleceu também, em junho de 1942, um departamento de propaganda de guerra, o Office of War Information (OWI), que procurou influenciar os filmes em produção, incluindo obras de ficção, que atraíam maior audiência. Embora não tivessem 
um estatuto vinculativo nem fossem sempre transmitidas por vias oficiais, as recomendações do OWI tornaram-se cada vez mais difíceis de ignorar pelos estúdios, sobretudo a partir de 1943, quando o Departamento de Censura passou a recusar licenças de exportação a produções que não fossem aprovadas pelo OWI (Doherty 1999, 3659; Koppes \& Black 1987, 48-112; McLaughlin \& Parry 2006, 15-23).

A guerra tornou-se num tema proeminente do cinema americano. Segundo Dorothy B. Jones, que dirigiu durante dois anos a secção de análise de filmes do OWI em Los Angeles, 374 das 1.313 obras de Hollywood estreadas entre 1942 e 1944 abordaram em primeiro plano questões relacionadas com o conflito em curso (Jones 1945, 2-3). Estas produções respondiam ao interesse do público, bem como a um apelo do presidente Franklin D. Roosevelt, que realçara a necessidade de promover compreensão sobre diferentes aspetos da guerra, incluindo a natureza do inimigo e dos aliados - as chamadas "Nações Unidas" (Jones 1945, 1-2; Schatz 1998, 101). O número traduz também a campanha ativa do OWI, que reconhecia explicitamente o poder propagandístico do cinema, sobretudo de entretenimento (Koppes \& Black 1987, 64). No verão de 1942, esta instituição distribuiu aos estúdios o Government Information Manual for the Motion Picture Industry, pedindo que, durante cada produção, se tivesse em conta questões como "Este filme vai ajudar a ganhar a guerra?" e "Se é um filme 'escapista', irá prejudicar o esforço de guerra ao criar um falso retrato da América, dos seus aliados ou do mundo em que vivemos?" (66). 5 Uma das preocupações centrais era apresentar a guerra como uma cruzada pela liberdade em que o inimigo, mais do que povos ou nações, era o próprio fascismo (248$250){ }^{6}$

No caso do tratamento dado a Portugal, colocavam-se em particular questões de ordem comercial e política. Com grande parte da Europa ocupada pelas forças do Eixo, este tornou-se num dos poucos espaços do continente europeu a exibir filmes americanos (Segrave 1997, 128). Algumas das maiores distribuidoras - MGM, Paramount, RKO, 20th Century-Fox - tinham sucursais em Portugal, que em 1944 albergava cerca de 285 salas abertas à exibição de obras dos EUA ("Potential World Market" 1944; Palmeiro 1946). Do ponto de vista estratégico, a neutralidade portuguesa tinha tanto de oportunidade como de desafio. Por um lado, Washington aproveitou o domínio de Hollywood sobre dois terços do mercado português: em 1943, o seu adido comercial fez eleger um homem da sua confiança para presidente do Grémio Nacional de Distribuidores de Filmes (ameaçando com dificuldades em receber obras dos EUA os sócios que votassem contra) e as distribuidoras norte-americanas passaram a exigir a exibição de documentários pró-Aliados a troco da cedência

\footnotetext{
${ }^{5}$ Todas as traduções do inglês são da responsabilidade do autor do artigo.

${ }^{6}$ A relação entre Hollywood e o OWI, embora colaborativa, foi marcada por tensões permanentes, em parte devido à preocupação do governo com os possíveis efeitos de cada filme na reputação externa dos EUA (Jones 1945, 13). Ainda assim, nunca, até aí ou desde então, foi tão intensa a convergência entre esta indústria e os desígnios estatais (Schatz 1998, 89).
} 
de filmes mais populares (Telo 1990, 80-82). Por outro lado, como veremos, as negociações em curso desaconselhavam produções que provocassem a ira do regime salazarista.

Embora a complexa teia de ponderações a nível criativo, técnico e político não tenha impedido a proliferação de narrativas desenroladas em espaço português, foi frequente o abandono de projetos encomendados, anunciados ou mesmo já iniciados. Em novembro de 1940, a MGM encarregou Edgar Selwyn de produzir Episode in Lisbon, que aplicaria a fórmula do clássico Grand Hotel (1932) - ou seja, várias personagens com histórias entrecruzadas reunidas num cenário frenético - ao cobiçado serviço de hidroavião (Boeing Clipper) que ligava o aeroporto marítimo de Cabo Ruivo a Nova Iorque. ${ }^{7}$ Os planos mantiveram-se pelo menos até março de 1941 ("O novo filme de Robert Taylor" 1941; Churchill 1941b); porém, a MGM acabou por engavetar o projeto. Na mesma altura, a pequena produtora Colonnade Pictures anunciou a intenção de produzir Last Clipper from Lisbon, uma longa-metragem a partir de uma história de Frank Clemente sobre uma futura invasão de Portugal pelos nazis ("Big Productions" 1941; "Colonnade Studios" 1941; "Hollywood Veteran" 1941). ${ }^{8}$ A empresa cessou atividade pouco depois, após ter completado apenas três filmes. ${ }^{9}$ Em 1943, a MGM propôs adaptar o romance Memo to a Firing Squad (Hedda 1943), no qual um grupo da Resistência procurava expor um pacto assinado no palácio de um general fascista português, em Lisboa, através do qual as forças do Eixo, fingindo promover a paz, preparavam uma nova guerra (Brennan 1943). No entanto, o OWI opôs-se veementemente à adaptação, pois a retórica do projeto punha em causa a possibilidade de colaboração das Nações Unidas no pós-guerra, sendo particularmente desrespeitosa para com a aliada União Soviética (Roth 1943).

A Warner Brothers parecia especialmente apostada em explorar o potencial dramático dos voos transatlânticos. Um dos seus produtores, Bryan Foy, procurou desenvolver uma história a partir do título Lisbon Clipper, convidando o correspondente de guerra Eric Sevareid a escrever o argumento. Sevareid escreveu um tratamento sobre um romance entre um vice-cônsul americano em Portugal e uma atriz checoslovaca perseguida pela Gestapo e por um jovem

\footnotetext{
7 A história tiraria partido da concentração cosmopolita desse porto e dos exorbitantes preços dos voos: um dos protagonistas era uma jovem, Hedy Lamarr, que procuraria seduzir um aventureiro, Robert Taylor, para ficar com o seu bilhete (Parsons 1940). O argumento foi encomendado a Howard Emmett Rogers e, mais tarde, a Albert Mannheimer (Shearer 2010:121,131).

8 A rodagem estava prevista para maio, com realização de John Reinhardt ("Film Studio Here" 1941).

${ }^{9}$ Lista de produções no site do AFI:

https://catalog.afi.com/Search?searchField=ProductionCompany\&searchText=Co lonnade\%20Pictures\%20Corp.\&sortType=sortByExactMatch (acedido em 30 de Abril de 2018).
} 
apaixonado (Cloud \& Olson 1996, 107). ${ }^{10}$ Em setembro e outubro de 1941, a imprensa menciona outros dois projetos intitulados Lisbon Clipper: uma comédia dramática, sobre um agente secreto britânico preocupado com a esposa durante uma missão que o levaria de Londres a Paris e Portugal, ${ }^{11} \mathrm{e}$ uma história de aventuras. ${ }^{12} \mathrm{O}$ intento da Warner foi reforçado pelo sucesso de Casablanca (1942), thriller romântico e político pejado de referências ao entreposto lisboeta na rota para os EUA. Em janeiro de 1943, o produtor desse projeto, Hal Wallis, convenceu o estúdio a comprar uma história passada na capital portuguesa, Passage to Lisbon, com o propósito de produzir um filme que parecesse uma continuação de Casablanca, repetindo parte do elenco ("“Casablanca' Follow Up” 1943; "Studios Buy” 1943; Parsons 1943b). ${ }^{13}$ Em abril desse ano, a Warner encarregou Wallis de reconfigurar essa ideia através da adaptação do recém-publicado romance The Conspirators (Parsons 1943a; Shearer 2010, 183), originando o filme discutido na última secção deste artigo.

A esta filmografia não concretizada podemos acrescentar projetos que, não tendo sido completamente abandonados, sofreram alterações significativas. Tal sucedeu com The Lady Has Plans (1942), uma comédia em torno de um caso de identidade trocada entre uma espia com planos secretos tatuados no corpo e uma repórter em Portugal que, consequentemente, é abordada por diversos espiões que procuram ver-lhe as costas. Entre as localizações e situações previstas no tratamento do filme que não chegaram à versão final encontravamse cenas passadas numa fábrica de conservas de sardinha com centenas de trabalhadores (que serviria de fachada para espiões nazis) e uma sequência num bairro portuário de Lisboa onde marinheiros atirariam dinheiro a uma dançarina em trajes menores antes de se envolverem numa violenta rixa (Birinski 1941, 12-14/61-65). Se, neste caso, a documentação disponível não permite aferir a razão dos cortes, o mesmo não se passa com Storm Over Lisbon (1944), thriller em que Martiza, uma dançarina checa, enfrenta uma rede de mercenários encabeçada por Deresco, dono de um casino no Estoril. Segundo relatórios internos do OWI, este gabinete ameaçou a produtora, Republic Pictures, com dificuldades de exportação caso o projeto não fosse alterado (Roth 1944). Em janeiro de 1944, o OWI avaliou negativamente o guião proposto, por considerar que este dava

\footnotetext{
10 Ainda que atraído pela causa nazi, o jovem acabaria por trair os alemães, o que permitia à atriz fugir com o vice-cônsul no Clipper para Nova Iorque, de certo modo antecipando o final de Casablanca.

${ }^{11}$ Argumento de Maurice Hanline e Jesse Lasky Jr, realização de Edward Sutherland (Churchill 1941c; Scheuer 1941).

12 Guião de Bert Granet a partir de um enredo de Gordon Wellesley e Basil Woon, realização de Robert Florey (Churchill 1941a; 1941d). Curiosamente, o único filme distribuído nos EUA durante a guerra cujo título aproveitou o imaginário associado a estes voos foi, em 1943, Lisbon Clipper Mystery, na verdade uma obra britânica da década anterior - Non-Stop New York (1937) - passada a bordo de um voo transatlântico a partir de Londres, sem ligação a Lisboa (Slide 1998, 171).

${ }^{13}$ A escolha de Lisboa acentuaria não apenas a sensação de continuação (é o destino do avião no final de Casablanca) mas possivelmente de repetição, pois a capital portuguesa inspirara em parte o ambiente do filme anterior, baseado numa peça cuja trama fora originalmente pensada como tendo lugar em Lisboa (Isenberg 2017, 6).
} 
uma imagem prejudicial da neutralidade portuguesa, nomeadamente ao apresentar Deresco como capaz de matar sem interferência da polícia. O OWI assumiu a posição de que, "em vista da importância estratégica do balanço delicado mantido por Portugal, um retrato desfavorável que de alguma maneira ofenda os portugueses pode ter ramificações internacionais", tendo enviado uma carta aos produtores a exigir a consulta de peritos em Washington relativamente à "matéria delicada" que era o uso de uma localização portuguesa (Cunningham 1944). Em linha com as sugestões do OWI, na versão final do filme foram eliminadas falas cínicas do vilão sobre a neutralidade de Portugal e Maritza passou a ser uma agente recrutada pelos serviços secretos portugueses, os quais, apostados em desmantelar a rede de espiões inconveniente para os Aliados, montam uma armadilha a Deresco.

Como este último exemplo demonstra, a construção da imagem de Portugal apresentada por Hollywood implicou por vezes considerações e consequências ao nível do discurso implícito sobre as práticas e opções políticas do regime português, especialmente no que toca ao seu posicionamento face aos dois campos em guerra. De modo a compreender mais aprofundadamente o alcance desse processo, as secções seguintes analisarão os casos quer de um projeto abandonado, quer de um projeto concluído após importantes alterações.

\section{The Gamblers: discursos abandonados}

O argumento de The Gamblers ("Os Jogadores") foi escrito por Samuel Guy Endore para a Warner Brothers. O tratamento data de 11 de julho de 1942 (Endore 1942a) e o guião completo é de 5 de setembro do mesmo ano (Endore 1942b). ${ }^{14} \mathrm{O}$ projeto não foi anunciado publicamente e é escassa a informação sobre as suas origens, inserido que está na vasta onda de projetos centrados na guerra elaborados nesse verão, na sequência do referido apelo de Roosevelt. Embora exista alguma bibliografia sobre Endore (Ramsey 2007, 77-214; Wald 2002, 1-6; Wald 2012, 313-16), não contém referências a The Gamblers. Este escritor nova-iorquino, que começou a trabalhar em Hollywood em 1935, foi ativista de causas antirracistas e membro do Partido Comunista dos EUA desde o final da década de trinta até aos anos cinquenta, sendo o seu esquerdismo a dimensão que mais tem atraído atenção póstuma, consequentemente focada em obras que se articulam mais claramente com essa vertente. ${ }^{15}$

\footnotetext{
14 Este guião não está datado, mas a data é identificada no relatório do OWI (Thorson 1942).

15 É o caso dos romances Babouk, sobre uma revolta de escravos no Haiti, e The Werewolf of Paris, passado na Comuna de Paris (Wald 1992; Foley 1993, 201202/325-326/342-343; Martin 2014). Embora The Gamblers seja declaradamente antifascista, a filiação comunista do autor não é tão evidente como, por exemplo, no filme pró-soviético Song of Russia (1944), cuja história é creditada a Endore. Para uma análise do teor propagandístico de Song of Russia, veja-se McLaughlin \& Parry 2006, 156-158.
} 
The Gamblers segue três alemães enviados a Lisboa pelo regime nazi com a missão de convencer as elites portuguesas a aceitar a construção de bases para submarinos alemães nos Açores e em Cabo Verde. Tendo aderido ao nazismo menos por convicção do que por comodismo, oportunismo e cobardia, cada um dos três atravessa uma crise existencial, numa dramatização do belicismo, do racismo e da violência do seu regime - Herman Kassel, engenheiro naval cujo filho morreu na frente de leste, sente-se dividido entre a fé na ciência e o uso desta para a guerra; Kurt Haberl, dono de uma fábrica de material militar, sente-se dividido entre o lucro e o amor pela esposa e filhos não-arianos; Hans Otto, poeta tornado propagandista, sente-se dividido entre a sua sensibilidade artística e a brutalidade nazi ao reencontrar um amigo, Keller, agora resistente antifascista em fuga. Fracassada a missão, os três procuram fugir, mas no fim optam resignadamente por regressar a Berlim e continuar a colaborar com o nazismo. São manipulados ao longo de todo o processo pelo agente da Gestapo Leopold Krause.

Para além do enredo esquemático, o guião propõe dispositivos modernistas que reforçam a componente alegórica da narrativa, conferindo à guerra em curso dimensões míticas. O filme abriria com um plano do firmamento que, em conjunto com a música, deveria criar "uma impressão do mistério do universo. Uma impressão do tempo e do espaço. E do homem." (Endore 1942b, 1). ${ }^{16}$ A ação seria enquadrada por um narrador omnisciente, a "Voz", descrito como o "espírito das Nações Unidas", que teria a voz de Keller (Cast of Characters). Na sequência inicial, a Voz comunicaria ao público que "Este filme é sobre ti! E a escolha que tu tens que fazer entre o bem e o mal. É sobre ti e a maior luta no mundo!" (1-5). ${ }^{17}$ Sublinharia ainda a ligação entre o neutro Portugal e o tema da escolha entre o bem e o mal, informando, sobre o plano de uma livraria com metade do espaço ocupado por propaganda pró-Eixo e a outra metade por propaganda pró-Aliados e o dono no centro: "Em nome da paz, carregar água nos dois ombros tornou-se a correta postura nacional." (24).

Embora Portugal possa ser visto como apenas mais um símbolo da luta que teria lugar na consciência de cada um, Endore não deixou de retratar a neutralidade portuguesa com mais especificidade e complexidade do que fizeram os filmes que foram concluídos. Esta neutralidade é um ponto central do argumento de The Gamblers, o qual confronta diferentes motivações em jogo, incluindo um inédito reconhecimento de que o alinhamento com o Eixo podia ser apelativo para as elites locais. No guião, os alemães procuram aliciar os

\footnotetext{
${ }^{16}$ A ficha técnica seria então sobreposta a um planetário, pirâmides, uma catedral e um observatório, "como que para mostrar a crescente perceção do homem quanto à vastidão e mistério do universo onde vive".

17 Em sucessivas interrupções, a Voz continuaria a evocar a transcendência da narrativa. Descreveria a evolução histórica do papel - enquanto as imagens seguiriam o percurso desde a árvore até à folha de papel -, para introduzir uma cena sobre refugiados impedidos de viajar por questões burocráticas (56-58) e comentaria que nos jogos de azar do Casino do Estoril se apostava "mais dinheiro do que o trabalho honesto pode ganhar ao longo de uma vida" após um súbito plano do planeta, que se transformaria numa bola de roleta (72-73).
} 
portugueses com uma retórica desenvolvimentista. Kassel mostra-se confiante: "Portugal vai sem dúvida receber de bom grado o nosso dinheiro e a nossa experiência em engenharia. Isso vai promover a industrialização do seu país." (Endore 1942b, 11). ${ }^{18}$ Numa cenachave, o trio nazi oferece um banquete a um grupo de personalidades influentes em Lisboa e projeta excertos de filmes de guerra alemães. Otto declara ter chegado a hora de Portugal optar por se juntar ao império nazi, recordando ameaçadoramente que o Eixo já conquistou a Polónia, a Noruega, a Bélgica, a França, a Jugoslávia e a Grécia. O discurso termina apelando não só à sede de lucro dos empresários portugueses, mas sobretudo ao seu patriotismo, ao afirmar que, através da integração na Nova Ordem hitleriana, Portugal retomará "o papel que em tempos teve no mundo" (46). Com uma única exceção, todos os convidados se levantam e fazem a saudação nazi, enquanto Otto exclama "Heil Hitler!" (44-47).

A exceção é o Conde da Veda, um aristocrata que questiona as promessas alemãs de partilha de poder (lembrando que Hitler quebrou promessas feitas aos russos, checoslovacos e noruegueses) e, num gesto dramático, oferece uma cópia do Tratado Anglo-Português para servir de contraponto (Endore 1942b, 48-50). Invoca assim de forma clara a relação privilegiada entre o neutro Portugal e o aliado Reino Unido. Quando Haberl e Kassel lhe perguntam se ele não quer que o seu país seja rico e industrializado, Veda responde que quer que o seu país seja feliz, ao contrário da bombardeada e esfomeada Polónia sob ocupação, e quer manter a sua integridade enquanto ser humano. O humanismo do conde é reforçado mais tarde, quando oferece o seu iate a um grupo de refugiados para que possam fugir da Europa (58$60)$.

Se o grupo de empresários personifica um lado de Portugal ameaçado ou tentado a colaborar com o Eixo e o Conde da Veda personifica um lado anglófilo e disposto a auxiliar os refugiados, a breve aparição de um candongueiro (ticket scalper) evoca ainda um outro lado do país, que explora imoralmente o conflito. Endore descreve este personagem como "simbólico daquela secção de Lisboa que pensa que a guerra é boa para o negócio", caracterizando-o como extravagante e aperaltado, ao contrário dos candongueiros novaiorquinos. Quando aborda o trio alemão com o objetivo de lhes vender bilhetes de barco - e, se necessário, passaportes ou vistos - a preços exorbitantes, o candongueiro garante que não se importa de negociar com antissemitas e que alguns dos seus melhores clientes são nazis (Endore 1942b, 124-147).

Ao ilustrar o submundo em torno da rota de fuga lisboeta, esta cena articula-se com momentos anteriores que incidem sobre o lado negro da neutralidade portuguesa. Por si só, a crise de refugiados não teria sido um tema exclusivo de The Gamblers; porém, o projeto apresenta uma abordagem especialmente enfática quanto à inaptidão de Lisboa para lidar com o problema. Após imagens de refugiados a

${ }^{18}$ Otto coloca a questão em termos mais absolutos, dizendo que os portugueses terão de escolher o que preferem ser: mortos ou milionários (19). 
mendigar, a lutar por acesso ao consulado dos EUA e a desesperar perante a máquina burocrática (Endore 1942b, 16-17/57-58), Endore propõe planos de um campo de concentração com arame farpado e de cabeças entre grades prisionais, enquanto a Voz explica que as autoridades portuguesas não sabem o que fazer com tantos refugiados sem documentos e, por isso, enviam-nos para a prisão ou para campos de concentração locais (58). ${ }^{19}$

Esta sugestão de uma postura opressiva é uma breve exceção num projeto que, de resto - e, aqui sim, em linha com os filmes produzidos -, não só não identifica o regime português como ditadura, como apresenta a sua capital de modo a contrastá-la com o ambiente de asfixia democrática do Eixo, imaginando um Portugal sem censura na imprensa nem conflituosidade social (Endore 1942a, 2/7). Em regra, as autoridades locais não parecem repressivas, mas sim desamparadas, incapazes de assegurar a segurança e a neutralidade do seu território, uma vez que o argumento de The Gamblers assenta na premissa de que a Gestapo opera impunemente em Portugal. Otto explica a Haberl que, embora os portuguesas tenham tentado impedir a polícia secreta alemã de entrar no país, agentes da Gestapo como Krause conseguiram infiltrar-se disfarçados de músicos (Endore 1942b, 11-12). Krause não só rapta o fugitivo Keller, como assassina o Conde da Veda, sem prestar contas à justiça. $^{20}$

Esse assassinato materializa um dos aspetos mais singulares de The Gamblers em comparação com os retratos da neutralidade portuguesa que chegaram aos ecrãs, nomeadamente a clara indicação de que as forças nazis estariam dispostas a matar portugueses para satisfazer os seus interesses e, portanto, a opção neutral poderia resultar num ataque militar alemão. Ainda antes da ameaça feita por Otto no banquete com os empresários, esta possibilidade já fora explicitada quer pela narração da Voz (Endore 1942b, 8-9), quer pelo diálogo entre os três protagonistas ao sobrevoar Lisboa - segundo Haberl, bastariam duas horas de bombardeamento e "todo o país seria nosso" (9-10).

Por último, The Gamblers distingue-se pelas evocações que faz da história portuguesa, sugerindo que, tal como Portugal deixara para trás o auge do seu império, era chegada a hora de a Alemanha fazer o mesmo. O guião pede imagens de monumentos arquitetónicos "da anterior grandeza de Portugal” (Endore 1942b, 17), incluindo da Praça Luís de Camões, cuja estátua serve de pretexto para Keller declarar que o maior poeta português escreveu sobre as viagens de Vasco da Gama (68), e do Convento de Cristo, cuja janela ornamentada é descrita como uma importante "relíquia dos dias em

\footnotetext{
${ }^{19}$ A referência a campos de concentração é particularmente impressionante, dada a conotação com a violência nazi - mesmo antes da perceção das suas reais dimensões -, ainda que este tipo de estrutura não fosse exclusivo da Alemanha: o próprio governo de Roosevelt encarcerou a população americana de ascendência japonesa em campos governamentais (Daniels, Taylor \& Kitano 2013).

${ }^{20}$ Esta sequência está ausente da cópia do guião da UCLA, à qual faltam doze páginas. É, no entanto, descrita com pormenor no tratamento. (Endore 1942a, 41-45).
} 
que o poder naval de Portugal governava os oceanos do mundo, quando o sol nunca se punha no seu império" (22). O ângulo da câmara deveria descer da janela para a rua onde pessoas andavam descalças, focando-se num "atraente par de pés" as mexer os dedos com prazer, enquanto a Voz explicaria que, embora "orgulhoso do passado imperial do seu país", o típico lisboeta preferia humildemente "o seu atual conforto" (22). O discurso sobre a antiga glória e a noção de que os desígnios imperiais eram um fardo do qual Portugal se tinha já libertado têm um tom menos acusatório do que se poderia esperar do autor do romance anti-esclavagista Babouk (Endore 1934), mas não deixa de estar subentendida uma provocadora comparação entre o expansionismo nazi e o colonialismo europeu. Destaquem-se as palavras do Conde da Veda ao despedir-se dos seus anfitriões nazis, alegando cansaço:

Nós portugueses - sabem - não temos essa energia de blitzkrieg. Há trezentos anos atrás possuíamos o maior império do mundo e os problemas que nos custou deixou-nos exaustos até hoje. Daqui a trezentos anos - talvez mais cedo - muito mais cedo - vocês alemães também estarão cansados. (50)

Ainda que seja tentador presumir critérios meramente comerciais na decisão da Warner de não dar seguimento a The Gamblers, a produtora - que, tudo indica, deu luz verde a Endore para transformar o tratamento em guião e, depois, pediu um parecer ao OWI -, aparentemente só abandonou o projeto após um relatório desencorajador por parte do departamento de propaganda do governo, com data de 9 de setembro de 1942. O relatório, escrito por Marjorie Thornson, afirmava que o OWI aprovava muitas das teses expressas no guião, mas queixava-se de que a alegoria central era algo confusa e a apresentação de ideias demasiado pregadora, em vez de dramática, o que punha em causa a sua eficácia. Para além disso, The Gamblers era considerado "puramente derrotista", o que poderia ter fins educativos mas não serviria para levantar a moral, sendo os finais construtivos mais indicados para esse efeito (Thorson 1942).

Quanto ao Portugal de The Gamblers, na leitura de Thorson, o país era "representado como tentando desesperadamente carregar água nos dois ombros" e o resultado era, no mínimo, infeliz: “A maioria dos portugueses parece inclinada a ceder à pressão do Eixo; um homem resiste, e embora tenha uma vitória moral, é morto por um dos agentes da Gestapo que permeiam o país”. Thorson depreendia que a moral do filme era que, se não se resistisse ativamente ao mal, acabava-se engolido por ele, mas mesmo essa conclusão não lhe parecia clara, pois aquele que tentava resistir (Conde da Veda) também acabava por ser engolido - e, por mais que o guião enfatizasse a sua vitória moral, esta não produzira "nada de prático". Para o OWI, portanto, o principal problema relacionado com Portugal era o modo como as personagens portuguesas se articulavam com o tema do filme, ainda que o relatório salientasse que o Departamento de Estado também teria algo a dizer sobre o tratamento dado a este país (Thorson 1942). Mesmo que a reprovação do projeto 
se tenha devido mais ao tom do guião do que à caracterização da neutralidade portuguesa, esta reação ajuda a explicar a gradual remoção de discursos semelhantes na produção de The Conspirators.

\section{The Conspirators: discursos transformados}

Como foi referido, em abril de 1943 a Warner comprou os direitos do livro The Conspirators ("Os Conspiradores") com vista a produzir um filme que repetisse a fórmula e o elenco - e, logo, o sucesso - de Casablanca. ${ }^{21}$ Tratava-se de um romance de Frederic Prokosch, escritor americano especializado em literatura de viagens. Chegado a Lisboa em novembro de 1939, Prokosch permaneceu ao longo de dois anos no Hotel Palácio Estoril, onde a convivência com refugiados e espiões inspirou The Conspirators, completado no verão de 1942, já após o regresso aos EUA (Greenfield 2010, 198-203/235-237). Passada inteiramente em Lisboa e na linha do Estoril em 1941, esta obra relata o percurso de um resistente antinazi holandês, Vincent Van der Lyn, até assassinar o agente alemão Hugo von Mohr, que o havia denunciado como espião às autoridades portuguesas, em parte porque ambos estavam envolvidos com a mesma mulher (Prokosch 1943). O tema e cenário coincidiam com os planos da Warner; porém, não bastava uma adaptação fiel para evocar Casablanca. Apesar da história de amor e do arco narrativo reminiscente de um thriller de espionagem, este era um livro soturno, composto sobretudo por passagens contemplativas e extensas descrições da atmosfera da cidade, no qual a maioria das personagens secundárias eram pouco mais que esboços enigmáticos. Consequentemente, a transição para um filme de aventuras romântico com potencial apelo de massas implicou sucessivas metamorfoses, incluindo a proposta e o abandono de diferentes discursos sobre a realidade portuguesa.

Embora identifique em Lisboa uma certa beleza melancólica, o livro de Prokosch apresenta a capital como opressiva e decadente. A repressão política é referida logo no primeiro capítulo, o qual introduz Vincent encarcerado numa prisão de Alfama (provavelmente baseada na cadeia do Aljube), ocupada no último ano pela "inundação de prisioneiros políticos" (Prokosch 1943, 6), incluindo o octogenário Innocencio, "um dos prisioneiros portugueses", que grita desesperadamente por justiça e contra a opressão dos pobres (12). Vincent alerta o seu contacto na Resistência, o revolucionário espanhol Pedro Quintanilla, que Lisboa se tornou num lugar "pouco saudável" e cada vez mais perigoso para a célula a que pertencem (58). Sucessivas personagens mostram-se frustradas e ansiosas por deixar

\footnotetext{
${ }^{21} \mathrm{O}$ desejo da Warner de repetir esse sucesso atribuindo aos membros da equipa de produção e elenco de Casablanca projetos com um misto semelhante de romance, aventura e propaganda pode ser visto em várias produções da altura, tais como To Have and Have Not (1944) e Passage to Marseille (1944). Sobre os esforços da Warner, ver Isenberg 2017, 201-208.
} 
Portugal, terra provinciana para onde se derramaram os restos da civilização europeia. ${ }^{22}$

Tendo escapado da prisão através do suborno de guardas, Vincent é seguido por polícias que sugerem a multiplicidade das simpatias ideológicas nacionais. Um agente, Fernando, parece próximo do Eixo: pergunta se Vincent é judeu e comunista e acusa os ingleses de serem ladrões já quase sem poder na Europa (Prokosch 1943, 120-125). Outro, Manuel Pereira, parece anglófilo - não só soa orgulhoso por a irmã ter casado com um inglês e preocupado por não ter notícias dos sobrinhos, como, numa breve cena, abdica da oportunidade de prender Vincent, dando a entender que apoia a sua causa (136-141). A decisão decorre de uma conversa em que Pereira revela receio quanto a Portugal, país "pequeno", "pobre" e "desamparado" (139). Também o seu superior, Capitão Almeida, descreve Portugal como "pobre" e "desamparado", embora "antigo e ilustre" (125). No entanto, Almeida mostra-se cético em relação às velhas categorias políticas ("As teorias não servem de nada quando o mundo está a arder.”; 123), confessando sofridamente que não compreende bem o que se passa no mundo e assumindo-se como um "patriota" a tentar fazer o melhor pelo país que ama (125).

Alguns destes elementos encontram-se presentes nas primeiras versões do guião de The Conspirators, tendo sido abandonados mais tarde. A exclusão dos mesmos não resultou de uma opção evidente tomada à partida, mas de um longo processo de produção. Hal Wallis encomendou a adaptação a Frederick Faust (conhecido como Max Brand), prolífico escritor de contos para revistas pulp, a quem coube elaborar rapidamente uma trama de aventuras a partir da limitada narrativa do romance de Prokosch. Faust, que submeteu dois tratamentos em abril de 1943 e um primeiro guião no final do mês seguinte (Faust 1943a, 1943b, 1943c), recorreu explicitamente ao guião abandonado de The Gamblers para adensar as fugidias personagens de The Conspirators. ${ }^{23}$ Insatisfeito com a trama proposta, Wallis retirou o projeto a Faust (Gruber 1967, 117). Elliot Paul submeteu um tratamento em junho, mais próximo do livro de Prokosh (Paul 1943), mas também não terá agradado ao produtor, visto que as suas propostas foram amplamente ignoradas nas versões seguintes. Ao longo do verão de 1943, Wallis - que costumava ter dois ou três argumentistas a trabalhar simultaneamente no mesmo projeto, sem o saberem, e depois construir guiões compostos de cenas de diferentes escritores - encomendou separadamente novas versões a Frank

\footnotetext{
${ }^{22}$ Aborrecido com a omnipresente letargia, o responsável pela espionagem alemã, Herr Schmidt, queixa-se que Camões e Vasco da Gama ainda pairam sobre o país como fantasmas, pois desde a sua "era dourada" que nada de relevo se passa em Portugal, exceto um terramoto, "uns poucos reis e rainhas", "uma batalha ou duas" e "inúmeras sardinhas" (47-48). As elites nacionais aparecem sob a forma do francófilo Conde José Caldelas e sua esposa, os quais organizam um banquete para aristocratas refugiados num castelo decorado com peles de animais de Moçambique e máscaras africanas (278).

${ }^{23}$ Nomeadamente, as personagens de Herr Schmidt - que Faust propôs caracterizar à imagem de Leopold Krause, o agente da Gestapo de Gamblers - e o Capitão Almeida, caracterizado à imagem do Conde da Veda (Faust 1943a, 2/5).
} 
Gruber, Lilian Hellman e Vladimir Pozner (Gruber 1967, 118-119, Pozner 1943). Quando se apercebeu desta situação, Gruber abandonou o projeto (Gruber 1967, 119), embora tivesse, em setembro, submetido um guião que retomava ideias e diálogos de Faust (Gruber 1943). O guião compósito constante do arquivo de Wallis contém diálogos adicionais de Ayn Rand (Wallis 1944) e material de uma versão assinada por Jack Moffitt, com data de fevereiro de 1944 (Moffitt 1944a).

A rodagem, realizada por Jean Negulesco, começou em março (Barton 2010, 142; Shearer 2010, 184), mas o processo sofreu uma nova reviravolta com o despedimento de Wallis, no início de abril, devido a disputas pessoais com o presidente do estúdio (Dick 2004, 79). Steve Trilling assumiu as funções de Wallis como diretor de produção da Warner (Finler 2003, 286) e o projeto de The Conspirators em concreto passou para o produtor Jack Chertok, que decidiu alterar substancialmente a história do filme (Barton 2010, 141). A pedido de Trilling, Moffitt entregou uma lista de sugestões a 10 de abril (Moffitt 1944b). Trilling reuniu também com Leo Rosten, que reescreveu diversas cenas, aproveitando parte do que já fora filmado e afastando ainda mais o argumento do livro (Rosten 1944). ${ }^{24}$ A produção, inicialmente planeada para terminar a 26 de abril de 1944, concluiu-se a 9 de junho e estreou a 20 de outubro desse ano, tendo obtido desprezo da crítica mas sucesso com o público (Shearer 2010, 186/192/193).

Uma das tendências mais flagrantes ao longo das sucessivas reescritas do argumento prende-se com o reconhecimento de diferentes simpatias ideológicas entre as autoridades portuguesas, praticamente reduzidas à dimensão anglófila. A personagem do agente Fernando - antissemita, anticomunista, anglófobo - não foi transposta para as adaptações, com exceção da proposta de Paul $(1943,57)$, na qual, mesmo assim, tem uma postura menos clara. ${ }^{25}$ Por outro lado, personagens não-anglófilas foram sendo reinterpretadas. Faust reimaginou o Capitão Almeida a partir da descrição do Conde da Veda no guião de The Gamblers. Propôs que Almeida fosse um "aristocrata português que está a sujar as mãos com assuntos policiais porque tem de tentar ajudar o seu país com dignidade e honra num período difícil da sua história", acrescentando que o "seu coração está todo com Inglaterra - a política estabelecida de Portugal há séculos mas quer caminhar sobre a corda da neutralidade até que seja seguro para o seu país avançar" (Faust 1943a, 5). ${ }^{26}$ A única nuance das autoridades passou então a ser entre a adesão rigorosa à neutralidade,

\footnotetext{
24 Para o argumento final, já bastante próximo do filme, ver Pozner/Rosten 1944b. 25 Ficou também ausente do filme uma breve referência, num dos guiões, à nacionalidade de um "Senhor Gama - exportações e importações - meio-português, meio-italiano - e cem porcento nazi..." (Wallis 1944, 146).

26 Por seu turno, Paul sugeriu tornar o francófilo Conde Caldelas num "nobre português pró-britânico", membro de um grupo antinazi (Paul 1943, 8).
} 
personificada por Almeida, ${ }^{27}$ e a disposição para colaborar com os Aliados, personificada pelo agente Pereira.

Pereira é, aliás, a personagem que melhor ilustra o crescente destaque dado à anglofilia, por ser uma figura periférica no texto de Prokosch, que vai ganhando peso até se tornar num importante elemento do guião. Em parte, a evolução sugere um dispositivo para evocar Casablanca: conferir a Pereira um arco semelhante ao do Capitão Renault nesse filme, ou seja, um polícia que começa por se apresentar como respeitante da neutralidade mas acaba por apoiar a Resistência. ${ }^{28}$ Nesse espírito, Gruber promoveu Pereira a capitão (e, consequentemente, Almeida a coronel), deu-lhe uma cena inicial na alfândega, a explicar aos recém-chegados a necessidade de respeitar a neutralidade de Portugal $(1943,3)$ e converteu a breve cena em que Pereira deixa escapar Vincent - inicialmente adaptada com fidelidade ao livro (Faust 1943c, 88-92) - num momento-chave do terceiro ato. Nas suas notas, Moffitt queixou-se de que o diálogo dessa cena era "extremamente inacreditável e lamechas" (1944b, 6). Rosten reescreveu então o momento de viragem -, deixando explícito que Pereira tem contas a ajustar com os nazis pela morte do cunhado inglês (Pozner \& Rosten 1944a,143) -, bem como a conversa na alfândega, com o propósito de fortalecer a cumplicidade entre Pereira e Vincent (Rosten 1944, 1/14-15). Acrescentou ainda uma sequência que torna mais ativo e determinante o apoio de Pereira: no clímax, depois de Vincent alvejar von Mohr, é Pereira quem mata definitivamente o vilão, quando este está prestes a disparar sobre o protagonista. Após salvar a vida do herói, o polícia atira ao mar a arma de Vincent, ilibando-o do tiroteio antes de o deixar deliberadamente fugir uma segunda vez (Conspirators 01h37m25s-01h38m14s).

Para além de criar um eco de Casablanca, a proeminência dada à aliadofilia das autoridades portuguesas explica-se pela crescente perceção, no decorrer do processo de escrita, de uma viragem da política operada por Portugal. O acordo com o Reino Unido para a concessão de facilidades militares nos Açores, assinado secretamente em agosto de 1943, entrou em vigor a 8 de outubro (Rosas 1994, 317). Revelando já alguma informação sobre a matéria (embora assumindo que o acordo abrangia o arquipélago cabo-verdiano), Gruber integrou no guião uma referência à presença dos britânicos nos Açores e Cabo Verde $(1943,3) .{ }^{29}$ A 14 de outubro, o Los Angeles Times especulou que The Conspirators provavelmente abordaria o acordo dos Açores (Schallert 1943). Uma semana depois, o Motion Picture Herald dava por adquirido o alinhamento português com os Aliados, comentando até que a Warner não estivera à altura da fama de antecipar notícias

\footnotetext{
${ }^{27}$ Na versão final, a atitude de Almeida mantém-se fiel à descrição de Faust como "a de um português patriota que insiste em manter a estrita neutralidade do seu país e aplicar as suas leis sem medo ou favor." (Faust 1943b, 25).

${ }^{28}$ Os limites deste paralelo são em si mesmos reveladores da generosidade do retrato das autoridades portugueses: ao contrário de Renault, que aparece inicialmente como corrupto e imoral, evocando a colaboração francesa com o nazismo antes de evocar a Resistência, Pereira é constantemente caracterizado como competente e honesto.

${ }^{29}$ Esta referência chegou até ao próprio filme (The Conspirators, 00h04m21s-27s).
} 
da guerra, pois esta produção não fora concluída a tempo de beneficiar da atenção dada à suposta viragem de Portugal ("Hollywood Scene" 1943).

Em paralelo com a expansão da dimensão colaborante, deu-se uma contração do discurso crítico da posição neutral portuguesa, presente em diferentes versões do guião. A versão de Paul não só aludia ao aproveitamento económico dos refugiados, ${ }^{30}$ como recuperava a passagem do livro em que Pereira assumia a vulnerabilidade de Portugal, temendo a expansão da guerra ao seu país. ${ }^{31}$ A versão compósita de Wallis continha ainda um momento em que, após a referência aos Açores, um agente alemão, Otto Lutzge, se dirigia a Pereira em termos ameaçadores: "Este tipo de neutralidade já levou à escravatura. O Capitão só tem de olhar para o mapa... Se eu não gostasse tanto de Portugal não o avisava.”, acrescentando: "Portugal tem um grande futuro - se -", sem oportunidade de concluir a frase (Wallis 1944, 7). Esta versão tinha também uma cena, claramente inspirada por The Gamblers, passada em frente a uma banca de jornais decorada, de um lado, com um retrato de Hitler e imprensa alemã e, do outro, com uma bandeira americana e uma edição do New York Times. Quando Vincent comentasse a diversidade da oferta, o vendedor responderia, resignadamente: "Isto é Portugal. Carregamos água em ambos os ombros.", ao que Vincent responderia: "Espero que nunca se molhem..." (11).

A insinuação de que a neutralidade era algo que punha em causa a segurança nacional, podendo suscitar um ataque alemão, foi sacrificada em nome de uma perspetiva cada vez menos ambígua sobre a posição portuguesa. Rosten cortou a cena da banca de jornais, de modo a "acelerar a história", argumentando que a conversa não fazia mais que repetir o que já tinha sido dito sobre a neutralidade de Portugal $(1944,2)$. Abreviou também o diálogo entre Lutzge e Pereira, de modo a que o agente alemão dissesse somente: "A neutralidade não basta. As vossas simpatias -", sendo interrompido por Pereira: "As minhas simpatias só me dizem respeito a mim, senhor! Eu faço o meu dever." (1). O restante diálogo dessa cena foi igualmente encurtado por Rosten, que insistiu na necessidade de evitar "pistas falsas que só confundem a audiência" (1). Na versão final, o discurso ficou ainda mais simplificado, com Lutzge a declarar a neutralidade portuguesa já não como insuficiente, mas como "unilateral" (The Conspirators 00h04m22s-30s). Por outras palavras, o que desagrada ao agente alemão já não é a opção pela neutralidade, mas sim a sua duvidosa implementação - ou seja, omite-se o potencial negativo da posição portuguesa (vulnerabilidade perante as forças do Eixo) e sublinha-se

\footnotetext{
30 O funcionário de uma estação queixava-se: "Subimos os preços para os estrangeiros, mas depois também temos que os pagar.” (Paul 1943, 58).

31 Pereira: "Somos sortudos em Portugal, até agora, talvez. Mas quem sabe por quanto tempo mais? O que podemos fazer? Nada. Nada! - Mandamos tropas para a Madeira, Cabo Verde, Açores. Mas apenas por orgulho." (Paul 1943, 75). No livro: p. 139. A noção de vulnerabilidade perpassava também o guião de Faust, que abria com a voz de Vincent a descrever a sensação de ver as luzes de Lisboa a partir do ar: "Parecia tudo mal. Parecia um desafio louco aos bombardeiros" (Faust 1943c, 1).
} 
o seu carácter positivo (é uma neutralidade colaborante, que prejudica os nazis).

A outra tendência notória ao longo do processo de adaptação é o esbatimento da repressão no Estado Novo, mais uma vez se distinguindo Portugal dos inimigos da liberdade. No guião de Faust, Almeida admitia o uso generalizado de técnicas de vigilância, ainda que desse a entender que era feito a contragosto, apenas devido ao clima de guerra: "Como Lisboa se tornou numa casa assombrada, cheia de furtividade e sussurros, tenho que usar desprezíveis postos de escuta e enviar espiões a todo o lado - pobres ratazanas que vendem as almas por uns poucos escudos." (1943c, 48). As versões seguintes deixaram cair o reconhecimento destas práticas. A própria prisão de Vincent foi despolitizada: ao contrário do que se passa no livro, já não é preso por espionagem, mas sim por invasão de propriedade (na versão de Faust) e por homicídio (a partir da versão de Gruber).

A tendência para o branqueamento das autoridades é ainda mais nítida no que toca à sequência prisional. A corrupção dos guardas nunca saiu do livro, tendo todos os argumentistas optado por variações de uma fuga excitante, em linha com a fórmula de outros filmes de prisão de Hollywood. Quanto ao estabelecimento, o tratamento de Paul é o único que procura captar o clima opressivo (ainda que desorganizado) sugerido por Prokosch:

Vemos, depois da panorâmica da cidade pitoresca, a velha prisão de Alfama, com a entrada da frente e a sede da polícia Internacional [sic] à beira de uma praça ensombrada por ulmeiros; guardas, não numerosos ou firmes pois a prisão está sobrelotada e com insuficiente pessoal; os prisioneiros letárgicos, a maioria políticos, descansando ou caminhando nas celas comunitárias, corredores e pátios murados, num calor fervilhante. [...] a sombra de um guarda, andando lentamente e monotonamente para a frente e para trás sobre a sombra violeta-cinzenta da torre que se espraia pelo pátio, move-se como um espectral pêndulo de autoridade. (11)

De resto, não só se perdeu a força da imagem de uma prisão populosa $^{32}$, como desapareceram as indicações de que se tratava de um estabelecimento com contornos políticos: para além de Vincent, o único prisioneiro visível é Antonio [sic], que chegou a ser um filósofo espanhol (Faust 1943c, 1) e um marinheiro antifascista italiano (Paul 1943, 7), mas acabou convertido num português conformado que admite estar preso por ter morto um homem que o traiu (The Conspirators 00h51m35s-53s).

Não obstante, Antonio protagoniza um dos poucos resquícios de um discurso potencialmente negativo sobre as condições de vida em Portugal. Quando Vincent foge da cela, Antonio apercebe-se de

\footnotetext{
${ }^{32}$ No filme, só se veem dois prisioneiros, pelo que a prisão parece praticamente deserta, dando a impressão de numerosos guardas patrulhando celas vazias (The Conspirators, 00h51m35s-00h53m16s; 00h56m52s-01h02m38s).
} 
que a porta ficou destrancada e sai hesitantemente para o corredor, mas acaba por encolher os ombros - segundo o guião, "como se soubesse que nunca escapará" (Pozner \& Rosten 1944a, 89) - e regressa à cela. ${ }^{33}$ Negulesco filmou a cena com um tom sombrio, acompanhando-a de música dramática (Conspirators 00h59m25s01h00m00s). Tendo sido cortada qualquer explicação para o comportamento do prisioneiro, para além do ar assustado e, depois, resignado, a sua reação poderá sugerir que lhe é indiferente estar lá fora ou cá dentro, como se o exterior fosse ele mesmo uma prisão, pelo menos para pessoas como Antonio. O contexto dado pelo resto do filme, porém, não sustenta essa interpretação. A classe popular, personificada por uma humilde aldeia em Cascais, não dá mostras de insatisfação com a sua condição, nem de temer o aparelho repressivo da ditadura (The Conspirators 01h21m17s-00h25m57s; 01h06m15s01h07m08s; 01h38m15s-01h40m00s). ${ }^{34}$ As autoridades não se revelam preocupadas com a população portuguesa, mas somente com a circulação de estrangeiros. ${ }^{35}$

A equiparação de Portugal a uma prisão, quando muito, pode então ser vislumbrada na experiência de alguns estrangeiros, embora também aqui o resultado filmado esteja aquém da imagem esboçada nos guiões. Quando Vincent atravessa o Cafe Imperio [sic], um planosequência capta conversas sobre vistos e planos de fuga em diferentes línguas, culminando num sucinto diálogo em que um homem afirma, em tom aflito: "Corro qualquer risco que me tire deste lugar!" (The Conspirators 01h08m36s-55s). Este curto trecho é não apenas uma rara herança das descrições de Prokosch sobre o desamparo dos refugiados, mas mais uma evocação de Casablanca, nomeadamente da montagem que introduz o Rick's Café Americain, com as mesas ocupadas por pessoas de várias nações, desesperadas por prosseguir viagem (Casablanca 01h07m20s-01h08m09s). O impacto da versão de The Conspirators, no entanto, é enfraquecido pelo facto de ter lugar num café luxuoso, com um quarteto de cordas, empregados aprumados e clientes com aspeto abastado. De fora ficou a passagem do guião de Wallis em que um empregado explicaria que os clientes do café estavam capazes de matar para obter vistos ou passaportes. ${ }^{36}$ Rand acrescentara ao empregado a seguinte fala (igualmente ausente do filme):

\footnotetext{
${ }^{33}$ No guião de Wallis, fica implícito que Antonio estaria assustado pela guerra, pois num diálogo anterior Vincent avisara-o sobre o terrível conflito em curso (1944, 84). No guião final, Vincent voltava para vir buscar Antonio e encontrava-o a chorar, amedrontado (Pozner \& Rosten 1944a, 90).

34 No filme, a única manifestação de medo refere-se ao distante mundo dominado pela Alemanha, quando um pescador confessa o terror que sentiu ao ser acusado de contrabandismo perto de Biarritz (The Conspirators, 01h24m15s-01h24m23s).

35 Veja-se as cenas no aeroporto, bem como a sequência em que agentes da polícia controlam os passaportes de transeuntes (The Conspirators, 00h03m00s00h06m02s e 00h26m53s-00h28m09s).

${ }^{36}$ Seguir-se-ia um plano de uma mesa com homens conspirativos, outra com homens a examinar um anel de diamantes e ainda outra com uma mulher a tentar forçadamente seduzir um homem solitário.
} 
Eles gastam todo o dinheiro que têm - e passam fome em pensões pestilentas. Depois - o explorador belga aparece no quarto com uma bala no cérebro - a condessa austríaca é presa por roubar a pulseira de safira - o professor checo afoga-se no Tejo... (Wallis 1944, 24a) ${ }^{37}$

Em vez deste contexto esquálido, Negulesco filma um ambiente sumptuoso, evitando que a ânsia de partir, expressa brevemente pelos refugiados, ponha em causa o contraste central entre uma Europa destruída pela guerra e uma Lisboa onde ainda há lugar para luxo e diversão.

Por fim, com a possível exceção do nome do Cafe Imperio - e da sua decoração com um mapa-mundo na parede -, referências ao declínio do poder de Portugal e à sua história colonial foram igualmente sacrificadas. Num provável eco do monólogo do Conde da Veda em The Gamblers, o guião de Wallis continha uma passagem em que Pereira alertava Lutzge: "Infelizmente fomos avisados pelo nosso passado. Outrora fomos uma potência mundial. Nos tempos de Vasco da Gama cada mendigo português possuía cinco escravos. E isso arruinou-nos. A escravatura tende a arruinar quem a pratica, Herr Lutzge." $(1944,8)$. A passagem não sobreviveu aos esforços de Rosten para polir a cena, tornando o diálogo menos "solto e divagante" (1944, 1).

Seja pela sobrevivência de resquícios dos vários guiões ou pela semi-autonomia da linguagem cinematográfica, é possível discernir no filme pequenos momentos ou pormenores que contrariam as tendências acima identificadas. Tal como nas suas restantes colaborações com o diretor de fotografia Arthur Edeson, ${ }^{38}$ Negulesco tende a envolver a tela em sombras profundas, criando um contraste chiaroscuro na linha do expressionismo alemão e do emergente film noir. Uma sequência violenta num beco lisboeta confere por momentos à capital portuguesa uma atmosfera relativamente sombria e opressiva (The Conspirators 01h09m40s-01h10m49s), de resto espelhada no próprio trailer, que sobrepõe a uma imagem deste momento a descrição "a cidade de ecos e sombras" (The Conspirators Trailer 00m20s-00m23s). O próprio OWI identificou algumas ambiguidades ao queixar-se, por exemplo, de que a facilidade com que Vincent foge da prisão sugeria uma força policial pouco eficiente e de que a presença do Coronel Almeida numa festa da Embaixada Alemã poderia soar suspeita, tendo consequentemente recomendado que The Conspirators não fosse distribuído em Portugal, onde o público se poderia "ressentir quanto ao retrato da sua neutralidade" (Gould 1944).

Não foram essas brechas, no entanto, que constituíram o mais claro legado do filme, mas sim o modo como firmou Lisboa entre os espaços associados por Hollywood a aventura e romance. Nas produções norte-americanas que posteriormente revisitaram a cidade

37 Esta fala abrevia uma descrição mais longa do livro de Prokosch $(1943,70-71)$.

38 The Mask of Dimitrios (1944), Three Strangers (1946) e Nobody Lives Forever (1946). 
- as mais proeminentes, durante o Estado Novo, foram Lisbon (1956) e A Man Could Get Killed (1966) - não encontramos fugas de prisão nem chefes da polícia suspeitos de serem benevolentes com o nazismo. Reaparecem, sim, restaurantes requintados, romance ao som de fado, alusões ao vinho, pescadores amigáveis e inspetores cúmplices com os protagonistas (sendo as autoridades portuguesas quem inevitavelmente pune os vilões no final), em suma, elementos centrais na narrativa que ou foram introduzidos pelos argumentistas ou ganharam especial destaque no decorrer do sinuoso percurso desde o livro até ao ecrã.

\section{Conclusão}

Se a II Guerra Mundial contribuiu decisivamente para a imagem cinematográfica de Portugal, os casos de estudo analisados demonstram que não foi imediatamente claro que imagem seria essa, tendo sido propostas e revistas diferentes visões que não chegaram ao ecrã, ora devido ao cancelamento de projetos, como no caso de The Gamblers, ora devido à drástica reformulação dos mesmos, como no caso de The Conspirators. O universo inicial de possibilidades deu lugar a um afunilamento da complexidade política de Portugal, nação oficialmente neutra com proximidade ideológica ao Eixo e negócios com o mesmo, mas também historicamente ligada ao Reino Unido e cada vez mais colaborante com (e estrategicamente importante para) o esforço de guerra anglo-americano. Desse processo de simplificação resultou a rejeição - ou minimização - de discursos que reconheciam o apelo de um eventual alinhamento com o Eixo (quanto mais não fosse, devido ao receio de um ataque alemão), a dimensão cínica do lucro feito à custa da guerra, a repressão e a incapacidade das autoridades de lidar com os refugiados, bem como a noção de que Portugal encabeçara em tempos um grande império, agora decadente.

Em parte, a redução discursiva reflete a influência da máquina de propaganda de Washington, a quem convinha distanciar Portugal do fascismo, quer para consumo interno (deixando claro que este possível parceiro não pertencia ao campo dos inimigos), quer para consumo externo (não hostilizando o regime salazarista ao questionar a sua neutralidade). Contudo, nem o poder do OWI era absoluto, nem a sua visão assim tão limitada - um documentário da série The March of Time, estreado em outubro de 1943, revelava uma maior nuance ao identificar o Estado Novo como uma ditadura semelhante à de Mussolini, com uma importante dimensão imperial e de lucro de guerra, incluindo a venda de volfrâmio à Alemanha (Portugal Europe's Crossroads). A explicação, portanto, passa também pela lógica dos estúdios que, na produção de ficção, apostavam na repetição de fórmulas de sucesso. No caso de Lisboa, foi dada prioridade ao aspeto mais reconhecível projetado por Casablanca: o de entreposto cosmopolita onde eram vividos os dramas de estrangeiros marcados pela guerra, sem grande interesse na dramatização dos problemas locais. Ao contrário da narrativa proposta em The Gamblers, nos filmes completados os protagonistas 
atuam em Portugal, mas não procuram atuar sobre Portugal. Mesmo a rede antifascista de The Conspirators, que opera clandestinamente no país, não só não é constituída por portugueses, como não é vista a agir contra o Estado português, que nada indica que considere inimigo. Numa era em que Hollywood dramatizou tantos povos europeus a resistir à repressão autoritária, ${ }^{39}$ os portugueses aparecem sem vontade nem necessidade de revolta, o seu regime desligado da vaga fascista que assola o resto do continente.

É dessa lógica redutora que resulta a implicação mais duradoura do contexto de guerra. Os filmes produzidos na altura foram a tal ponto fundacionais na codificação de Portugal na ficção audiovisual norte-americana que os discursos omitidos - por oposição aos discursos sobreviventes, que enfatizavam a dimensão aliadófila ou o potencial turístico-romântico do país - não encontraram expressão em obras posteriores, mesmo quando estas foram já produzidas sem a supervisão do OWI. Este momento constitutivo foi especialmente marcante, pois a II Guerra Mundial tornou-se ela própria fundacional para o modo como Washington definiu as subsequentes relações internacionais, concebendo a Guerra Fria como uma extensão do conflito anterior, com os EUA de novo responsáveis por combater o totalitarismo (Adler \& Paterson 1970). Em linha com essa visão, nas décadas seguintes uma representação formulaica preservou o papel de Portugal no imaginário herdado da guerra, continuando a menorizar o carácter oscilante e ambíguo da política portuguesa evidenciado pela historiografia. Assim, nem os empresários pró-nazis nem o candongueiro imoral de The Gamblers se converteram em estereótipos lisboetas. Ausentes ficaram também as alusões a prisioneiros políticos e ao passado esclavagista, cortadas de The Conspirators. Omitidos das narrativas de Hollywood, esses elementos foram mais facilmente omitidos da narrativa da Guerra Fria. Sem espaço na ficção, permaneceram confinados à realidade.

\section{BIBLIOGRAFIA}

Adler, Les K.; \& Thomas G. Paterson. 1970. "Red Fascism: The Merger of Nazi Germany and Soviet Russia in the American Image of Totalitarianism, 1930's-1950's." The American Historical Review 75(4), 1046-1064.

Andrade, Luís. 2008. "The Azores and the Second World War." In Franklin Roosevelt and the Azores During the Two World Wars, organizado por Luís Nuno Rodrigues, 337-350. Ponta Delgada: Fundação Luso-Americana para o Desenvolvimento.

Antunes, José Freire. 1995. Roosevelt, Churchill e Salazar: a luta pelos Açores, 1941-1945. Alfragide: Ediclube.

\footnotetext{
${ }^{39}$ Dos polacos de To Be or Not to Be (1942) aos checoslovacos de Hangmen Also Die! (1943), passando pelos espanhóis de For Whom the Bell Tolls (1943), bem como numerosos filmes sobre a resistência francesa, norueguesa e alemã (McLaughlin \& Parry 2006, 112-116/174-187/201-214).
} 
Barton, Ruth. 2010. Hedy Lamarr: The Most Beautiful Woman in Film. Lexington, KY: University Press of Kentucky.

Birinski, Leo. 1941. Tratamento de "The Palace of a Thousand Lies". 27 março. 00952, Paramount Pictures Scripts. Margaret Herrick Library. Academy of Motion Pictures Arts and Sciences [AMPAS]. Los Angeles, CA.

Brennan, Frederick Hazlitt. 1943. Memo to a Firing Squad. Nova Iorque, NY: Alfred A. Knopf.

Churchill, Douglas W. 1941a. "News of Hollywood", The New York Times, 19 setembro.

. 1941b. "Screen News Here and in Hollywood", The New York Times, 13 março.

. 1941c. "Screen News Here and in Hollywood", The New York Times, 17 setembro.

. 1941d. "Screen News Here and in Hollywood", The New York Times, 3 outubro.

Cloud, Stanley, e Lynne Olson. 1996. The Murrow Boys: Pioneers on the Front Lines of Broadcast Journalism. Boston, MA: Houghton Mifflin Company.

Cunningham, William S. 1944. Carta para William Gahagan. 31 março. Box 3526. Entry 567-4742245. NC148. Record Group 208. Records of the OWI. National Archives and Records Administration [NARA]. College Park, MD.

Daniels, Roger, Sandra C. Taylor, e Harry H. L. Kitano, org. 2013 [2a edição] Japanese Americans: From Relocation to Redress. Seattle, WA: University of Washington Press.

Dias, Fernando Rosa. 2015. "As cores da Cidade Branca - Lisboa no ecrã: olhares do cinema estrangeiro sobre a cidade de Lisboa." In $O$ Chiado e o Cinema. Do Cinematógrafo ao Videomapping. Artes na Esfera Pública, organizado por José Quaresma, 177201. Lisboa: Instituto Camões, Associação dos Arqueólogos Portugueses.

Dick, Bernard F. 2004. Jack Warner: Producer to the Stars. Lexington, KY: University Press of Kentucky.

Doherty, Thomas. 1999 [edição revista]. Projections of War: Hollywood, American Culture, and World War II. Nova Iorque, NY: Columbia University Press.

Endore, Guy. 1942a. Tratamento de "The Gamblers". 11 junho. Box 42. Collection 279 (S. Guy Endore papers, 1925-1970). Charles E. Young Research Library. University of California, Los Angeles [UCLA]. Los Angeles, CA.

Endore, Guy. 1942b. Guião de "The Gamblers". Box 42. Collection 279 (S. Guy Endore papers, 1925-1970). Charles E. Young Research Library. UCLA. Los Angeles, CA. 
Endore, Guy. 1991 [1934]. Babouk. Nova Iorque, NY: Monthly Review Press.

Faust, Frederick. 1943a. Tratamento de "The Conspirators". 9 abril. Folder 8. Box 74. United Artists Collection: Series 1.2. Wisconsin Center for Film and Theater Research [WCFTR]. Madison, WI.

Faust, Frederick. 1943b. Tratamento de "The Conspirators". 15 abril. Folder 9. Box 74. United Artists Collection: Series 1.2. WCFTR. Madison, WI.

Faust, Frederick. 1943c. Guião de "The Conspirators". 29 maio. Folder 10. Box 74. United Artists Collection: Series 1.2. WCFTR. Madison, WI.

Finler, Joel W. 2003. The Hollywood Story. Londres/Nova Iorque, NY: Wallflower Press.

Foley, Barbara. 1993. Radical Representations: Politics and Form in U.S. Proletarian Fiction, 1929-1941. Durham: Duke University Press.

Gould, Peggy. 1944. Relatório sobre "The Conspirators". 7 outubro. Box 3514. NC148567-4741004. Record Group 208. Records of the OWI. NARA. College Park, MD.

Greenfield, Robert. 2010. Dreamer's Journey: The Life and Writings of Frederic Prokosch. Newark, NJ: University of Delaware Press.

Gruber, Frank. 1943. Guião de "The Conspirators". 11 setembro. Folder 3. Box 75. United Artists Collection: Series 1.2. WCFTR. Madison, WI.

Gruber, Frank. 1967. The Pulp Jungle. Los Angeles, CA: Sherbourne Press.

Hedda, Hopper. 1943. "Looking at Hollywood", Chicago Tribune, 16 março.

Isenberg, Noah. 2017. We'll Always Have Casablanca. The Life, Legend, and Afterlife of Hollywood's Most Beloved Movie. Nova Iorque, NY: W.W. Norton \& Company.

Jones, Dorothy B. 1945. "The Hollywood War Film: 1942-1944." Hollywood Quarterly 1 (1), 1-19.

Koppes, Clayton R., e Gregory D. Black. 1987. Hollywood Goes to War: How Politics, Profits and Propaganda Shaped World War II Movies. Londres: I.B. Tauris.

Leitz, Christian. 2001. Sympathy for the Devil: Neutral Europe and Nazi Germany in World War II. Nova Iorque, NY: New York University Press.

Loff, Manuel. 2008. O Nosso Século É Fascista!” O Mundo Visto por Salazar e Franco (1936-1945). Porto: Campo das Letras. 
Lopes, Rui. 2017a. "An Oasis in Europe: Hollywood Depictions of Portugal during World War II." Journal of Contemporary History 52(2), 375-398.

2017b. "Fado and Fatima: Salazar's Portugal in US Film Fiction." Film History: An International Journal 29(3), 52-75.

Louçã, António. 2000. Hitler e Salazar: comércio em tempos de guerra, 1940-1944. Lisboa: Terramar.

Martin, Carl Grey. 2014. "Guy Endore's Dialectical Werewolf." Le Monde Diplomatique. 15 setembro https://mondediplo.com/outsidein/guy-endore-s-dialecticalwerewolf (acedido a 28.04.2018)

Mateus, João Mascaranhas. 2010. "Uma cidade de espionagem internacional. Lisboa Segundo Hollywood." Metakinema 7. Disponível

em http://www.metakinema.es/metakineman7s4a2JoaoMascare nhasMateus_Lisbon_International_Intrigue_Hollywood.html (acedido a 28.04 .2018 )

McLaughlin, Robert L., e Sally E. Parry. 2006. We'll Always Have the Movies: American Cinema During World War II. Lexington, KY: University Press of Kentucky.

Meneses, Filipe Ribeiro. 2010. Salazar: A Political Biography. Nova Iorque, NY: Enigma Books.

Moffitt, Jack. 1944a. Guião de "The Conspirators". 12 fevereiro. Folder 7. Box 75. United Artists Collection: Series 1.2. WCFTR. Madison, WI.

Moffitt, Jack. 1944b. Sugestões para "The Conspirators". 19 abril. Folder 2. Box 76. United Artists Collection: Series 1.2. WCFTR. Madison, WI.

Moreli, Alexandre. 2018. "The War of Seduction: The AngloAmerican Struggle to Engage with the Portuguese Ruling Elite (1943-1948)" The International History Review 40(3), 654-682.

Ninhos, Cláudia. 2013. "Portugal e a Segunda Guerra Mundial. A Neutralidade Portuguesa." In Salazar, Portugal e o Holocausto, organizado por Irene Flunser Pimentel e Cláudia Ninhos, 345412. Lisboa: Temas e Debates - Círculo de Leitores.

Palmeiro, João de Moraes. 1946. "Portuguese 1944 Admissions Total Near 18,500,000”, Motion Picture Herald, 19 janeiro.

Parsons, Louella O. 1940. "Clipper Film Planned for Lamarr-Taylor." The Philadelphia Inquirer, 8 novembro. . 1943a. "Gossip of the Screen", The Morning News, 24 abril . 1943b. "Lisbon to Be Locale Of New War Picture", The Philadelphia Inquirer, 6 fevereiro. 
Paul, Elliot. 1943. Tratamento de "The Conspirators". 1 junho. Folder 1. Box 75. United Artists Collection: Series 1.2. WCFTR. Madison, WI.

Pozner, Vladimir. 1943. Guião de "The Conspirators". 18 outubro. Folder 4. Box 75. United Artists Collection: Series 1.2. WCFTR. Madison, WI.

Pozner, Vladimir, e Leo Rosten. 1944a. Guião de "The Conspirators". 24 março - 2 junho. 13. Paul Henreid papers. Margaret Herrick Library. AMPAS. Los Angeles, CA.

Pozner, Vladimir, e Leo Rosten. 1944b. Guião de "The Conspirators". 49. Jean and Dusty Negulesco papers. Margaret Herrick Library. AMPAS. Los Angeles, CA.

Prokosch, Frederic. 1943. The Conspirators. Londres/Nova Iorque, NY: Harper \& Brothers Publishers.

Ramsey, Joseph G. 2007. Red Pulp: Radicalism and Repression in midtwentieth century U.S. "genre" fiction. Tese de doutoramento. Boston, MA: Tufts University.

Ribeiro, António Lopes. 1941. "Lisboa, Encruzilhada de Estrelas." Animatógrafo, 13 janeiro.

Rodrigues, Luís Nuno. 2008. "Franklin D. Roosevelt and the Azores in World War II." In Franklin Roosevelt and the Azores During the Two World Wars, organizado por Luís Nuno Rodrigues, 351364. Ponta Delgada: Fundação Luso-Americana para o Desenvolvimento.

Rosas, Fernando. 1994. História de Portugal, vol.7: O Estado Novo (1926-1974). Lisboa: Círculo de Leitores.

Rosten, Leo. 1944. Comentários a "The Conspirators". 24 abril. Folder 3. Box 76. United Artists Collection: Series 1.2. WCFTR. Madison, WI.

Roth, Sandy. 1943. Relatório sobre "Memo to a Firing Squad". 22 março. OWI script reviews. Margaret Herrick Library. AMPAS. Los Angeles, CA.

Roth, Sandy. 1944. Relatório sobre "Storm over Lisbon". 31 março. Box 3526. Entry 567-4742245. NC148. Record Group 208. Records of the OWI. NARA. College Park, MD.

s.a. 1941. "Big Productions Outlined By Colonnades Pictures", The Miami Daily News, 25 março.

s.a. 1941. "Colonnade Studios Gets Second Recording Unit", The Film Daily, 24 abril.

s.a. 1941. "Film Studio Here Plans New Feature", The Miami Daily News, 6 abril.

s.a. 1941. "Hollywood Veteran Stakes All On Movie-Making Here", The Miami Daily News, 29 março. 
s.a. 1941. "O novo filme de Robert Taylor para a M-G-M passa-se em Lisboa!”, Animatógrafo, 1 março.

s.a. 1943. “Casablanca' Follow Up Now Planned”, The Milwaukee Sentinel, 5 fevereiro

s.a. 1943. "Studios Buy 55 Stories in January, February", Motion Picture Herald, 27 março

s.a. 1943. "The Hollywood Scene”, Motion Picture Herald, 23 outubro.

s.a. 1944. "Potential World Market 60,985 Houses, U.S. Says", Motion Picture Herald, 16 setembro.

Schallert, Edwin. 1943. "Conspirators' Timely Warner Bros. Subject”, The Los Angeles Times, 14 outubro.

Schatz, Thomas. 1998. "World War II and the Hollywood 'War Film'." In Refiguring American Film Genres, organizado por Nick Browne, 89-128. Los Angeles, CA: University of California Press.

Scheuer, Philip K. 1941. "Poll Reveals Flynn Favorite of Juveniles", The Los Angeles Times, 16 setembro.

Segrave, Kerry. 1997. American Films Abroad: Hollywood's Domination of the World's Movie Screens from the 1890s to the Present. Jefferson, NC: McFarland.

Shearer, Stephen Michael. 2010. Beautiful: The Life of Hedy Lamarr. Nova Iorque, NY: St. Martin's/Dunne.

Slide, Anthony. 1998. Banned in the U.S.A.: British Films in the United States and Their Censorship, 1933-1966. Londres/Nova Iorque, NY: I.B. Tauris.

Telo, António José. 1990. Propaganda e Guerra Secreta em Portugal (1939-45). Lisboa: Perspectivas e Realidades.

Telo, António José. 2000. A Neutralidade Portuguesa e o Ouro Nazi. Lisboa: Quetzal Editores.

Thorson, Marjorie. 1942. Relatório sobre "The Gamblers". 9 setembro. Box 3516. NC 148 Entry 567. Record Group 208. Records of the OWI. NARA. College Park, MD.

Wald, Alan. 1992. "The Subaltern Speaks.” Monthly Review, 43(11), 17-29.

. 2002. Exiles from a Future Time: The Forging of the MidTwentieth Century Literary Left. Chapel Hill: University of North Carolina Press.

. 2012. American Night: The Literary Left in the Era of the Cold War. Chapel Hill: University of North Carolina Press.

Wallis, Hal. 1944. Guião revisto de "Conspirators". 22 fevereiro - 25 março. 418. Hal Wallis papers. Margaret Herrick Library. AMPAS. Los Angeles, CA. 


\section{FILMOGRAFIA}

36 Hours. Realizado por George Seaton. MGM. EUA. 1965. 115 min.

A Bullet for Joey. Realizado por Lewis Allen. United Artists. EUA. 1955. $87 \mathrm{~min}$.

A Man Could Get Killed. Realizado por Ronald Neame \& Cliff Owen. Universal Pictures. EUA. 1966. 97 min.

'A Thief is a Thief', It Takes a Thief. Realizado por Leslie Stevens. ABC. EUA. 09.01.1968. 90 min.

Affectionately Yours. Realizado por Lloyd Bacon. Warner Bros. EUA. 1941. $88 \mathrm{~min}$.

'Blind Spot', Man with a Camera. Realizado por Gerald Mayer. ABC. EUA. 05.12.1958. $30 \mathrm{~min}$.

Casablanca. Realizado por Michael Curtiz. Warner Bros. EUA. 1942. $102 \mathrm{~min}$.

Don't Raise the Bridge, Lower the River. Realizado por Jerry Paris. Columbia Pictures. EUA. 1968. 99 min.

Flight to Hong Kong. Realizado por Joseph M. Newman. United Artists. EUA. 1956. 88 min.

For Whom the Bell Tolls. Realizado por Sam Wood. Paramount Pictures. EUA. 1943. 170 min.

Forbidden Passage. Realizado por Fred Zinnemann. MGM. EUA. 1941. $21 \mathrm{~min}$.

Grand Hotel. Realizado por Edmund Goulding. MGM. EUA. 1932. 112 $\min$.

Hangmen Also Die! Realizado por Fritz Lang. United Artists. EUA. 1943. $134 \mathrm{~min}$.

Hook, Line and Sinker. Realizado por George Marshall. Columbia Pictures. EUA. 1969. 92 min.

International Lady. Realizado por Tim Whelan. United Artists. EUA. 1941. $102 \mathrm{~min}$.

Jewels of Brandenburg. Realizado por Eugene Ford. 20 ${ }^{\text {th }}$ Century-Fox. EUA. 1947. 64 min.

Journey for Margaret. Realizado por W.S. Van Dyke. MGM, EUA. 1942. 81 min.

Lisbon. Realizado por Ray Milland. Republic Pictures. EUA. 1956. 90 $\min$.

'Lisbon', Biff Baker, U.S.A. Realizado por Herschel Daugherty e John English. CBS. EUA. 19.02.1953. $30 \mathrm{~min}$.

Nobody Lives Forever. Realizado por Jean Negulesco. Warner Bros. EUA. 1946. $100 \mathrm{~min}$. 
Non-Stop New York. Realizado por Robert Stevenson. Gaumont British. Reino Unido. 1937. 72 min.

One Night in Lisbon. Realizado por Edward H. Griffith. Paramount Pictures. EUA. 1941. $97 \mathrm{~min}$.

Passage to Marseille. Realizado por Michael Curtiz. Warner Bros. EUA. 1944. $109 \mathrm{~min}$.

Pickup Alley. Realizado por John Gilling. Columbia Pictures. EUA/Reino Unido. 1957. $92 \mathrm{~min}$.

Portugal - Europe's Crossroads. Realizado por [não identificado]. Time, Inc. EUA. 1943. $19 \mathrm{~min}$.

'Sink U-116!', Convoy. Realizado por Don McDougall. NBC. EUA. 12.11.1965. $60 \mathrm{~min}$.

Song of Russia. Realizado por Gregory Ratoff. MGM. EUA. 1944. 107 min.

Storm Over Lisbon. Realizado por George Sherman. Republic Pictures. EUA. 1944. 86 min.

The Conspirators. Realizado por Jean Negulesco. Warner Bros. EUA. 1944. $101 \mathrm{~min}$.

The Conspirators Original Theatrical Trailer. Realizado por Jean Negulesco. Warner Bros. EUA. 1944. 2 min.

The Fallen Sparrow. Realizado por Richard Wallace. RKO. EUA. 1943. $94 \mathrm{~min}$.

The Hairy Ape. Realizado por Alfred Santell. United Artists. EUA. 1944. $92 \mathrm{~min}$.

The House on $92^{\text {nd }}$ Street. Realizado por Henry Hathaway. 20 $0^{\text {th }}$ Century-Fox. EUA. 1945. 88 min.

The Lady Has Plans. Realizado por Sidney Lanfield. Paramount Pictures. EUA. 1942. $77 \mathrm{~min}$.

The Last Flight. Realizado por William Dieterle. First National Pictures. EUA. 1931. 76 min.

'The Last Laugh', Wire Service. Realizado por [não identificado]. ABC. EUA. 20.05.1957. 60 min.

'The Last Man', Blue Light. Realizado por Walter Grauman. ABC. EUA. 12.01.1966. $30 \mathrm{~min}$.

The Last Run. Realizado por Richard Fleisher. MGM. EUA. 1971. 95 min.

'The Lisbon Beat', Madigan. Realizado por Boris Sagal. NBC. EUA. 03.01.1973. $75 \mathrm{~min}$.

The Mask of Dimitrios. Realizado por Jean Negulesco. Warner Bros. EUA. 1944. 95 min.

'The Master's Touch Affair', The Man from U.N.C.L.E. Realizado por John Brahm, NBC. EUA. 16.10.1967. 60 min. 
The Russia House. Realizado por Fred Schepisi. MGM. EUA. 1990. 122 min.

The Secret Door. Realizado por Gilbert L. Kay. Allied Artists. EUA/Reino Unido. 1964. 72 min.

Three Hearts for Julia. Realizado por Richard Thorpe. MGM. EUA. $1942.83 \mathrm{~min}$.

Three Strangers. Realizado por Jean Negulesco. Warner Bros. EUA. 1946. $92 \mathrm{~min}$.

To Be or Not to Be. Realizado por Ernst Lubitsch. United Artists. EUA. $1942.99 \mathrm{~min}$.

To Have and Have Not. Realizado por Howard Hawks. Warner Bros. EUA. 1944. 100 min.

'Two Loves I Have', Schlitz Playhouse of Stars. Realizado por Roy Kellino. CBS. EUA. 28.08.1953. $30 \mathrm{~min}$.

Voice in the Wind. Realizado por Arthur Ripley. United Artists. EUA. 1944. $85 \mathrm{~min}$. 